\title{
Controle biológico da podridão radicular e promoção de crescimento em pepino hidropônico com microrganismos de manguezais
}

\author{
Élida Barbosa Corrêa(1), José Abrahão Haddad Galvão(2) e Wagner Bettiol(2)
}

\begin{abstract}
(1)Universidade Estadual Paulista, Faculdade de Ciências Agronômicas, Departamento de Produção Vegetal, Setor Defesa Fitossanitária, Caixa Postal 237, CEP 18603-970 Botucatu, SP. E-mail: elidabcorrea@yahoo.com.br (2)Embrapa Meio Ambiente, Rodovia SP-340, Km 127,5, Caixa Postal 69, CEP 13820-000 Jaguariúna, SP. E-mail: abrahao@cnpma.embrapa.br, bettiol@cnpma.embrapa.br
\end{abstract}

Resumo - O objetivo deste trabalho foi avaliar a capacidade de microrganismos de manguezais para controlar a podridão radicular causada por Pythium aphanidermatum e para promover o crescimento em pepino hidropônico (Cucumis sativus). Avaliaram-se 19 microrganismos quanto ao controle da doença em mini-hidroponia. Os microrganismos mais promissores para esse fim - Gordonia rubripertincta SO-3B-2 e a mistura dos isolados G. rubripertincta SO-3B-2, MB-P3A-49, MB-P3-C68 e SO-3L-3, de Pseudomonas stutzeri, e Bacillus cereus AVIC-3-6 - foram, posteriormente, testados quanto à promoção de crescimento do pepineiro, em casa de vegetação. Microrganismos de manguezais podem ter importância funcional no controle biológico da podridão radicular causada por $P$. aphanidermatum e na promoção do crescimento do pepineiro cultivado em hidroponia. Os microrganismos G. rubripertincta SO-3B-2 e P. stutzeri MB-P3A-49 são promissores na promoção do crescimento das plantas não infestadas com o patógeno.

Termos para indexação: Bacillus cereus, Cucumis sativus, Gordonia rubripertincta, Pseudomonas stutzeri, Pythium aphanidermatum, bioprospecção.

\section{Biological control of root rot and growth promotion in hydroponic cucumbers by mangrove microorganisms}

\begin{abstract}
The objective of this work was to evaluate the capacity of mangrove microorganisms to control root rot, caused by Pythium aphanidermatum, and to promote growth in hydroponic cucumbers. Nineteen microorganisms were evaluated for controlling the disease in small-scale hydroponic units. The promising microorganisms - Gordonia rubripertincta SO-3B-2, and the combination of strains (G. rubripertincta SO-3B-2, MB-P3A-49, MB-P3-C68 and SO-3L-3 of Pseudomonas stutzeri, and Bacillus cereus AVIC-3-6 were subsequently evaluated in hydroponic cucumbers, in the greenhouse. Mangrove microorganisms can have an important functional role in the biological control of root rot caused by P. aphanidermatum, and in the growth promotion of cucumber plants cultivated in hydroponic systems. Gordonia rubripertincta SO-3B-2 and P. stutzeri MB-P3A-49 are promising growth promoters for non-infected plants.
\end{abstract}

Index terms: Bacillus cereus, Cucumis sativus, Gordonia rubripertincta, Pseudomonas stutzeri, Pythium aphanidermatum, bioprospection.

\section{Introdução}

Os sistemas hidropônicos, caracterizados por elevada densidade de plantas, uniformidade genética, baixa diversidade de microrganismos e circulação da solução nutritiva, são ambientes propícios à ocorrência de epidemias de podridão radicular. A podridão radicular é a principal doença em cultivos hidropônicos e afeta, em diferentes graus, todas as espécies cultivadas nesse sistema (Paulitz \& Bélanger, 2001). Espécies de straminipilas do gênero Pythium são os principais agentes causais da doença em hidroponia, sendo Pythium aphanidermatum (Edson) Fitzp. o mais importante (Sutton et al., 2006). Além da podridão radicular, os sintomas típicos da doença são subdesenvolvimento, diminuição da produção e murcha das plantas (Zheng et al., 2000; Owen-Going et al., 2003; Corrêa et al., 2010).

A principal forma de controle é a preventiva, com o uso de água sem o patógeno e mudas sadias. Atualmente, os controles genético e químico não estão disponíveis para o produtor, pois não há variedades comerciais resistentes à doença, nem agrotóxicos registrados para uso em hidroponia no Brasil. O manejo da doença, que inclui práticas de sanitização, desinfestação do sistema hidropônico e minimização dos fatores de estresse do desenvolvimento vegetal (Sutton et al., 2006), é um desafio para produtores e técnicos. Uma alternativa que tem sido avaliada é o controle biológico realizado pela introdução de microrganismos antagônicos ao

Pesq. agropec. bras., Brasília, v.46, n.2, p.130-136, fev. 2011 
patógeno, indutores de resistência e promotores de crescimento de plantas, na solução nutritiva ou no substrato de cultivo (Paulitz et al., 1992; Paulitz \& Bélanger, 2001; Khan et al., 2003; Chatterton et al., 2004; Corrêa, 2006; Liu et al., 2007; Corrêa et al., 2010). Entretanto, a baixa adaptação dos agentes de biocontrole introduzidos no ambiente hidropônico, muitas vezes isolados de ambientes terrestres, diminui a eficiência do controle da doença (Khan et al., 2003; Corrêa, 2006).

Microrganismos de manguezais são adaptados às concentrações e às flutuações de salinidade e aos baixos teores de oxigênio (Bashan \& Holguin, 2002; Sahoo \& Dhal, 2009), característicos de ambientes hidropônicos. Assim, o isolamento de antagonistas a Pythium pode aumentar as possibilidades de adaptação e estabelecimento dos microrganismos introduzidos nesses ambientes.

O objetivo deste trabalho foi avaliar a capacidade de microrganismos de manguezais para controlar a podridão radicular causada por $P$. aphanidermatum e para promover o crescimento em pepino (Cucumis sativus L.) hidropônico.

\section{Material e Métodos}

A seleção de microrganismos foi realizada a partir de quatro isolados de bactérias produtoras de biossurfactantes (Gordonia rubripertincta SO-3B-2 e Pseudomonas stutzeri MB-P3A-49, MB-P3-C68 e SO-3L-3) do manguezal em Bertioga, SP (235' $46^{\prime \prime}$, $\left.96^{\circ} 12^{\prime} 50^{\prime \prime} \mathrm{W}\right)$ (Reyes, 2009); cinco isolados de fungos mitospóricos epifíticos do manguezal de Cananéia, SP $\left(25^{\circ} 05^{\prime} 40 " \mathrm{~S}, 47^{\circ} 58^{\prime} 16^{\prime \prime} \mathrm{W}\right)$ [L-1-1, L-1-3, L-2-7, isolados de mangue-branco (Laguncularia sp.); R-2-4, isolado de mangue-vermelho (Rhizophora mangle L.) e A-1-1, isolado de mangue-preto (Avicennia sp.)]; e dez isolados de bactérias esporogênicas do manguezal de Maceió, AL (09³1'27"S, 35 35'4"W), da rizosfera de plantas de mangue-preto e mangue-vermelho. As bactérias esporogênicas foram isoladas com a técnica de isolamento para Bacillus spp. (Bettiol, 1995). Os demais microrganismos eram provenientes da coleção de culturas do Laboratório de Microbiologia Ambiental da Embrapa Meio Ambiente, e o isolado de P. aphanidermatum (SPC 1973), obtido em plantas de pepino, pertence à coleção de culturas do Instituto de Botânica de São Paulo.
Na primeira fase, a seleção de potenciais agentes de biocontrole da podridão radicular foi realizada em plântulas de pepino cultivadas em minissistema hidropônico, composto por frascos de penicilina contendo solução nutritiva. Os isolados de bactérias esporogênicas foram avaliados em dois experimentos, e os demais microrganismos foram avaliados em um único experimento para cada grupo de microrganismos. Sementes de pepino cv. Safira (Sakata Seed América, Bragança Paulista, SP) foram germinadas em caixas "Gerbox" contendo papel de filtro umedecido em água destilada autoclavada. As sementes permaneceram no escuro por um dia e sob luz contínua por três dias. Após esse período, as plântulas foram transferidas para frascos de penicilina contendo $15 \mathrm{~mL}$ de solução nutritiva preparada com água destilada autoclavada com condutividade elétrica de $1,1 \mathrm{mS} \mathrm{cm}{ }^{-1}$ (kit de solução nutritiva composto por macro e micronutrientes produzido pela Qualifértil, São Paulo, SP), e acondicionadas em câmara de crescimento Conviron modelo CMP3244 (Controlled Environments Limited, Asheville, North Carolina, EUA), com fotoperíodo de 12 horas de luz, a $28 \pm 1^{\circ} \mathrm{C}$, durante 20 dias. A iluminação da câmara de crescimento foi fornecida por quatro lâmpadas incandescentes Philips $60 \mathrm{~W}$ e quatro lâmpadas Sylvania Cool White VHO 115 W. Os isolados de bactérias esporogênicas foram multiplicados em meio de cultura batata-dextrose-ágar (BDA) e as bactérias produtoras de biossurfactantes em meio "tryptic-soy-agar" por 48 horas, a $25^{\circ} \mathrm{C}$, sob luz constante. A multiplicação dos fungos ocorreu em meio BDA, a $25^{\circ} \mathrm{C}$, sob luz constante, durante cinco dias.

A produção de zoósporos de $P$. aphanidermatum foi realizada pela técnica adaptada de Rahimian \& Banihashemi (1979), que consiste no cultivo do patógeno em meio de cultura V8 $(100 \mathrm{~mL}$ de suco V8; 2 g de $\mathrm{CaCO}_{3} ; 16 \mathrm{~g}$ de ágar em $900 \mathrm{~mL}$ de água deionizada) em placas de Petri, por 72 horas, a $25^{\circ} \mathrm{C}$. Após este período, metade do conteúdo do meio de cultura com crescimento do patógeno foi transferida para outra placa, em que foram adicionados aproximadamente $20 \mathrm{~mL}$ de água destilada esterilizada. As culturas foram incubadas novamente por 72 horas, quando houve nova troca de água. Depois da segunda troca de água, as culturas foram incubadas a $22 \pm 1^{\circ} \mathrm{C}$, e, após aproximadamente 4 horas, os zoósporos foram liberados. A concentração de zoósporos na suspensão 
foi estimada pela vibração de $5 \mathrm{~mL}$ das amostras em microtubos em Vortex por $30 \mathrm{~s}$, com contagem dos zoósporos em hemacitômetro.

Os microrganismos de manguezais foram introduzidos na solução nutritiva pela adição de suspensões na concentração final de $10^{6}$ células $\mathrm{mL}^{-1}$. A infestação da solução nutritiva com zoósporos de $P$. aphanidermatum foi realizada dois dias após a introdução dos microrganismos de manguezais. Suspensões de $7 \times 10^{3}$ e $1 \times 10^{4}$ zoósporos $\mathrm{mL}^{-1}$ de $P$. aphanidermatum foram respectivamente utilizadas no primeiro e no segundo experimentos com bactérias esporogênicas, e suspensões de $4 \times 10^{3}$ zoósporos $\mathrm{mL}^{-1}$ foram utilizadas para os demais tratamentos. O tratamento apenas com $P$. aphanidermatum e a solução nutritiva do tratamento testemunha não receberam as suspensões com os microrganismos de manguezais.

A avaliação da mortalidade das plântulas e da incidência do patógeno nas raízes foi realizada ao final do experimento. A incidência de $P$. aphanidermatum nas raízes foi avaliada por plaqueamento de cinco fragmentos de raízes de cada repetição, em meio de cultura ágar-água ( $20 \mathrm{~g}$ de ágar em $1.000 \mathrm{~mL}$ de água destilada) acrescido dos antibióticos ampicilina (250 $\left.\mathrm{mg} \mathrm{L}^{-1}\right)$ e rifampicina $\left(10 \mathrm{mg} \mathrm{L}^{-1}\right)$, após autoclavagem. Depois de sete dias de incubação, foram observadas as estruturas reprodutivas sexuadas (anterídios, oogônios e oósporos) e assexuadas (esporângios) do patógeno em microscópio óptico.

Os isolados microbianos que se destacaram no controle da doença em plântulas cultivadas no minissistema hidropônico foram estudados quanto à capacidade de controlar a doença e promover o crescimento em pepino hidropônico, em condições de casa de vegetação. As bactérias esporogênicas isoladas foram identificadas por meio do perfil dos ácidos graxos da membrana celular. A avaliação do controle biológico dos isolados pré-selecionados foi realizada com sementes de pepino cv. Safira, semeadas em substrato à base de casca de pinus (Multiplant, Terra do Paraíso, Holambra, SP) previamente autoclavado por 1 hora, a $120^{\circ} \mathrm{C}$ e acondicionado em vasos de plástico de $400 \mathrm{~mL}$. Após a emissão da primeira folha verdadeira, as plantas foram irrigadas com solução

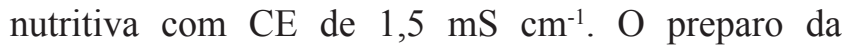
solução nutritiva foi realizado ao misturar-se $250 \mathrm{~mL}$ da solução concentrada A, constituída por, $1.600 \mathrm{~g} \mathrm{de}$ nitrato de cálcio e $150 \mathrm{~g}$ de Conmicros, (Conplant, Campinas, SP) em $10 \mathrm{~L}$ de água e $250 \mathrm{~mL}$ da solução concentrada B, constituída por, $2.000 \mathrm{~g}$ de nitrato de potássio, $400 \mathrm{~g}$ de fosfato monoamônio e $1.200 \mathrm{~g}$ de sulfato de magnésio em $10 \mathrm{~L}$ de água, em $100 \mathrm{~L}$ de água. Plantas com 30 e 36 dias de desenvolvimento foram tratadas com os microrganismos previamente selecionados com aplicação de suas suspensões, na concentração final de $1 \times 10^{6}$ células $\mathrm{mL}^{-1}$ de substrato. O substrato foi infestado com suspensão do patógeno na concentração final de $3 \times 10^{3}$ zoósporos $\mathrm{mL}^{-1}$ de substrato. A multiplicação dos microrganismos foi realizada conforme descrito anteriormente.

Após 22 dias, foi avaliada a massa de matéria seca do sistema aéreo, radicular e total das plantas, e a incidência do patógeno nas raízes. O monitoramento da temperatura do ar, na casa de vegetação, e do substrato contido nos vasos foi realizado diariamente.

Para verificar o potencial de promoção de crescimento em pepino hidropônico com bactérias produtoras de biossurfactantes, foram realizados dois experimentos. No primeiro experimento, sementes de pepino foram semeadas em vasos contendo $400 \mathrm{~mL}$ do substrato autoclavado por 1 hora, a $120^{\circ} \mathrm{C}$, com introdução dos microrganismos na concentração de $1 \times 10^{6}$ células $\mathrm{mL}^{-1}$ de substrato, aos 30 e 36 dias de desenvolvimento das plantas. A avaliação da massa de matéria seca do sistema aéreo, radicular e total das plantas foi realizada após 22 dias da segunda introdução dos microrganismos. No segundo experimento, foram utilizados vasos com $800 \mathrm{~mL}$ contendo substrato autoclavado por 1 hora, a $120^{\circ} \mathrm{C}$, e as plantas foram tratadas com suspensões bacterianas para atingir a concentração final de $1 \times 10^{9}$ ufc $\mathrm{mL}^{-1}$ de substrato, aos 7 e 13 dias de desenvolvimento das plantas. A avaliação das massas das plantas foi realizada 20 dias após a segunda introdução dos isolados bacterianos. No primeiro experimento, a multiplicação dos isolados bacterianos foi realizada conforme descrito anteriormente, e, no segundo, foi realizada em meio de cultura "tryptic-soy-broth" por 24 horas, a $28^{\circ} \mathrm{C} \pm 1^{\circ} \mathrm{C}$, sob agitação de $150 \mathrm{rpm}$, sendo a concentração ajustada por meio de espectrofotômetro (550 nm).

Os experimentos de seleção de microrganismos de manguezais em mini-hidroponia foram arranjados em delineamento inteiramente casualizado, e os experimentos de controle biológico e promoção de crescimento em casa de vegetação foram arranjados em blocos casualizados. Nos experimentos de seleção de microrganismos, foram utilizadas dez repetições para o experimento com fungos, oito repetições para 
o primeiro experimento, com bactérias esporogênicas, e sete repetições para o segundo experimento, com bactérias esporogênicas e bactérias produtoras de biossurfactantes. Nos experimentos em casa de vegetação, foram utilizados quatro blocos e quatro repetições. Os dados foram analisados pela ANOVA, e as médias comparadas pelo LSD ("least square difference"). Foi utilizado o SAS (SAS Institute, 2007) para a análise dos experimentos.

\section{Resultados e Discussão}

Entre os isolados de rizobactérias esporogênicas de plantas de mangue-preto (AVIC-3-3, AVIC-3-5, AVIC-3-6 e AVIC-3-9) e mangue-vermelho (SR1-3-2, SR1-3-4, SR1-3-6, SR2-2-2, SR2-2-6 e SR2-3-2), o isolado AVIC-3-6 de Bacillus cereus proporcionou maior sobrevivência das plântulas
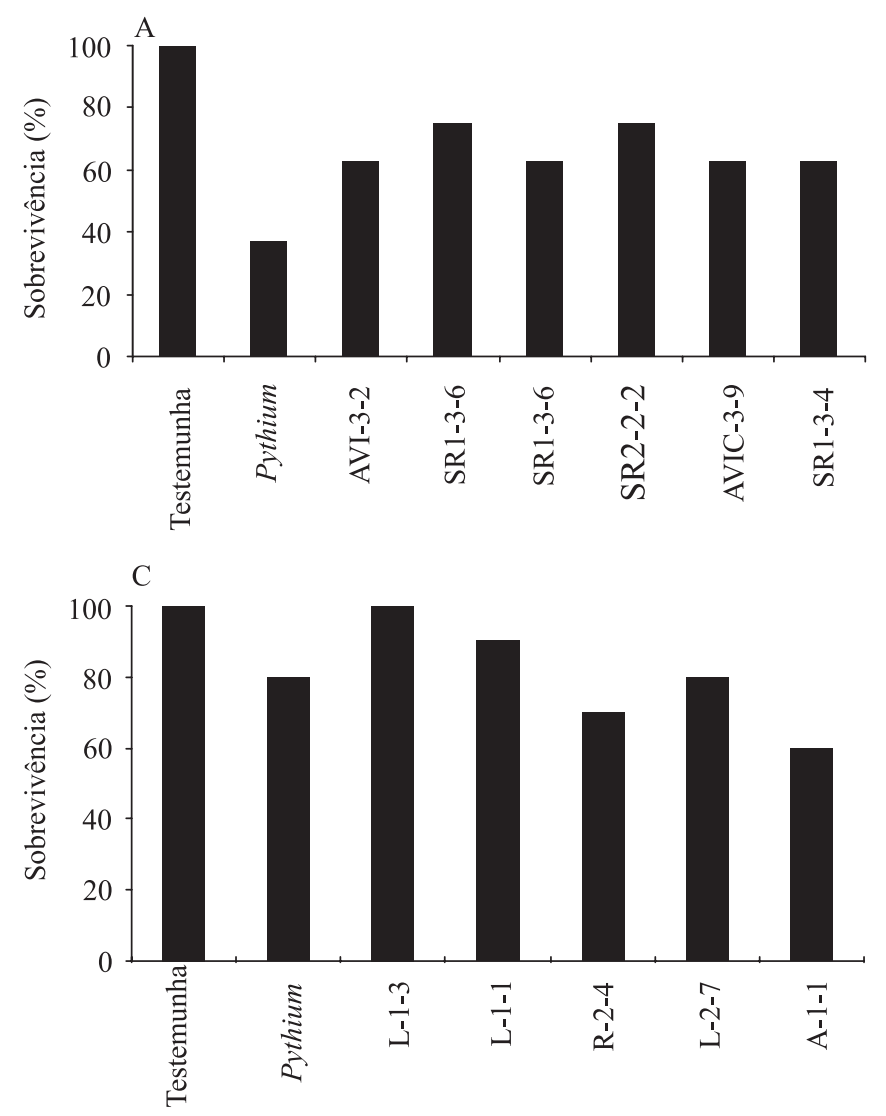

(71\%) inoculadas com o patógeno; no entanto, não diferiu estatisticamente do tratamento controle, apenas com $P$. aphanidermatum, que apresentou $43 \%$ de sobrevivência das plantas (Figura 1 B). A aplicação dos demais isolados de bactérias esporogênicas e dos isolados fúngicos também não aumentou a sobrevivência das plântulas (Figuras 1 A e C).

A infestação da solução nutritiva com o isolado bacteriano produtor de biossurfactante SO-3B-2 de G. rubriperticta, e com a mistura de isolados propiciou $100 \%$ de sobrevivência das plantas, o que diferiu estatisticamente do tratamento com $P$. aphanidermatum (Figura 1 D). Os outros isolados MB-P3A-49, MB-P3-C68 e SO-3L-3 de P. stutzeri não aumentaram a sobrevivência. Apesar de o isolado SO-3B-2 de G. rubriperticta e de a mistura de isolados aumentarem a sobrevivência das plântulas (Figura 1), as bactérias produtoras de biossurfactantes, as bactérias esporogênicas
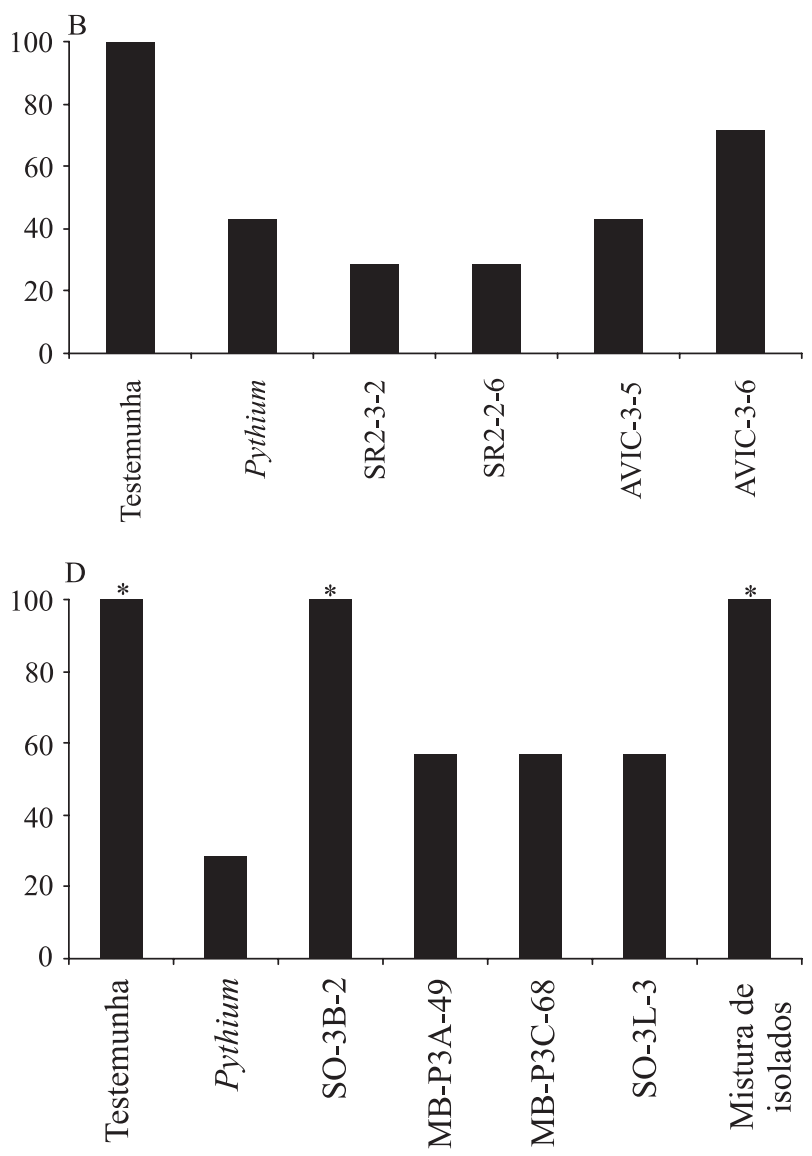

Figura 1. Sobrevivência (\%) de plântulas de pepino após: A e D, introdução de microrganismos de manguezal na solução nutritiva; A e B, infestação com Pythium aphanidermatum e inoculação com bactérias esporogênicas; C, inoculação com fungos; D, inoculação com bactérias produtoras de biossurfactantes. *Diferença significativa entre os tratamentos com isolados e o tratamento controle, apenas com o patógeno, pelo teste LSD, a 5\% de probabilidade. 
e os fungos não diminuíram a incidência do patógeno nas raízes (100\% nas plântulas com solução nutritiva infestada). O teste de seleção de agentes de controle biológico da podridão radicular foi similar ao realizado por Paulitz et al. (1992), com plântulas de pepino em mini-hidroponia. Os autores encontraram correlação entre o teste em mini-hidroponia e o teste em sistema hidropônico no controle da podridão radicular causada por $P$. aphanidermatum, o que indica a validade da metodologia empregada na seleção.

Não foram verificadas diferenças estatísticas significativas entre os tratamentos do experimento com adição de $B$. cereus AVIC-3-6 e bactérias produtoras de biossurfactantes no substrato infestado com $P$. aphanidermatum (Tabela 1). No experimento com B. cereus AVIC-3-6, a incidência do patógeno nas raízes do tratamento com $P$. aphanidermatum foi de $77 \%$, enquanto, nas raízes das plantas que receberam B. cereus AVIC-3-6 em substrato infestado com o patógeno, foi de $56 \%$. O patógeno foi recuperado em $6 \%$ das raízes do tratamento testemunha, mas não foi recuperado nas raízes das plantas em que B. cereus AVIC-3-6 foi aplicado sem a infestação do patógeno (Tabela 1).

O isolado $B$. cereus AVIC-3-6 não protegeu as plantas dos danos causados pelo patógeno em pepino. Entretanto, Liu et al. (2007) verificaram que, em crisântemo hidropônico, a aplicação de $B$. cereus HY06 na solução nutritiva suprimiu o desenvolvimento da podridão radicular causada por P. aphanidermatum, independentemente da temperatura da solução nutritiva ser alta $\left(32^{\circ} \mathrm{C}\right)$ ou moderada $\left(24^{\circ} \mathrm{C}\right)$. No presente trabalho foram registradas temperaturas elevadas $-36^{\circ} \mathrm{C}$ de temperatura do ar e $34^{\circ} \mathrm{C}$ de temperatura do substrato de cultivo das plantas -, que podem ter afetado a efetividade de biocontrole de B. cereus AVIC-3-6, pois elevadas temperaturas aumentam a suscetibilidade das plantas cultivadas em hidroponia à podridão radicular (Sutton et al., 2006).

No experimento com bactérias produtoras de biossurfactantes, a incidência do patógeno nas raízes foi de $100 \%$ no tratamento com $P$. aphanidermatum, de $87 \%$ com G. rubripertincta SO-3B-2 e de $65 \%$ com a mistura de isolados. O patógeno não foi recuperado nas raízes das plantas do tratamento testemunha (Tabela 1). Apesar de não ter sido verificado efeito dos isolados bacterianos produtores de biossurfactantes, a síntese de biossurfactantes pode ser considerada um importante mecanismo de controle da podridão radicular em hidroponia. Biossurfactantes são substâncias de superfície ativa, com composição química variada, produzidas por bactérias e fungos, e capacidade de lisar células sem parede celular. Essas substâncias são utilizadas para inativar zoósporos, como os de Pythium spp., Phytophthora spp. e Plasmopara spp., importantes estruturas de infecção de patógenos que ocorrem em hortaliças cultivadas em sistemas

Tabela 1. Efeito da introdução de microrganismos de manguezais no substrato de cultivo hidropônico de plantas de pepino, um a seis dias antes da inoculação ou não com Pythium aphanidermatum, sobre a massa de matéria seca das plantas e a incidência do patógeno nas raízes, 22 dias após a inoculação das plantas com o patógeno ${ }^{(1)}$.

\begin{tabular}{|c|c|c|c|c|}
\hline \multirow[t]{2}{*}{ Tratamento } & \multicolumn{2}{|c|}{ Massa de matéria seca $(\mathrm{g})$} & \multirow[t]{2}{*}{ Total } & \multirow{2}{*}{$\begin{array}{l}\text { Incidência de Pythium } \\
\text { aphanidermatum (\%) }\end{array}$} \\
\hline & Aérea & Radicular & & \\
\hline & \multicolumn{4}{|c|}{ Bacillus cereus } \\
\hline Testemunha & $8,00^{\mathrm{ns}}$ & $0,60 \mathrm{ab}$ & $8,59^{\mathrm{ns}}$ & $6 \mathrm{~b}$ \\
\hline Bacillus cereus & $7,36^{\mathrm{ns}}$ & $0,70 \mathrm{a}$ & $8,06^{\mathrm{ns}}$ & - \\
\hline Bacillus cereus + Pythium aphanidermatum & $7,61^{\mathrm{ns}}$ & $0,59 \mathrm{ab}$ & $8,20^{\mathrm{ns}}$ & $56 \mathrm{a}$ \\
\hline Pythium aphanidermatum & $7,18^{\mathrm{ns}}$ & $0,49 b$ & $7,67^{\mathrm{ns}}$ & $77 \mathrm{a}$ \\
\hline \multirow[t]{2}{*}{$\mathrm{CV}(\%)$} & 19,1 & 43,6 & 18,9 & 41,4 \\
\hline & \multicolumn{4}{|c|}{ Bactérias produtoras de biossurfactantes } \\
\hline Testemunha & $8,39^{\mathrm{ns}}$ & $0,92^{\text {ns }}$ & $9,31^{\mathrm{ns}}$ & - \\
\hline Gordonia rubripertincta + Pythium aphanidermatum & $8,05^{\mathrm{ns}}$ & $0,75^{\mathrm{ns}}$ & $8,80^{\mathrm{ns}}$ & $87^{\mathrm{ns}}$ \\
\hline Mistura de isolados + Pythium aphanidermatum & $8,51^{\mathrm{ns}}$ & $0,82^{\mathrm{ns}}$ & $9,33^{\text {ns }}$ & $65^{\mathrm{ns}}$ \\
\hline Pythium aphanidermatum & $7,93^{\mathrm{ns}}$ & $0,67^{\mathrm{ns}}$ & $8,60^{\mathrm{ns}}$ & $100^{\mathrm{ns}}$ \\
\hline $\mathrm{CV}(\%)$ & 11,9 & 42,1 & 12,9 & 25,7 \\
\hline
\end{tabular}

Pesq. agropec. bras., Brasília, v.46, n.2, p.130-136, fev. 2011 
hidropônicos (De Jonghe et al., 2005; Nielsen et al., 2006).

A introdução da mistura de bactérias produtoras de biossurfactantes $\left(1 \times 10^{6}\right.$ células $\left.\mathrm{mL}^{-1}\right)$ no substrato de cultivo de pepino hidropônico aumentou $\mathrm{o}$ desenvolvimento da massa de matéria seca total das plantas em 10\% (Tabela 2). Gordonia rubripertincta SO-3B-2 e P. stutzeri MB-P3A-49, na concentração de $1 \times 10^{9}$ ufc $\mathrm{mL}^{-1}$ de substrato, promoveram o incremento da massa de matéria seca do sistema radicular em 36 e

Tabela 2. Efeito da introdução de bactérias produtoras de biossurfactantes (Gordonia rubripertincta SO-3B-2 e Pseudomonas stutzeri MB-P3A-49, MB-P3-C68 e SO-3L-3) no substrato de cultivo hidropônico de pepino, 30 e 36 dias após a semeadura das plantas, aos 22 dias após a segunda inoculação do substrato com os microrganismos, sobre a massa de matéria seca das plantas.

\begin{tabular}{lccc}
\hline Tratamento & \multicolumn{2}{c}{ Massa de matéria seca $(\mathrm{g})$} & \multirow{2}{*}{ Total } \\
\cline { 2 - 3 } & Aérea & Radicular & \\
\hline Testemunha & $7,75 \mathrm{ab}$ & $0,54^{\mathrm{ns}}$ & $8,29 \mathrm{~b}$ \\
Gordonia rubripertincta & $7,42 \mathrm{~b}$ & $0,64^{\mathrm{ns}}$ & $8,07 \mathrm{~b}$ \\
Mistura de isolados & $8,44 \mathrm{a}$ & $0,70^{\mathrm{ns}}$ & $9,14 \mathrm{a}$ \\
\hline CV $(\%)$ & 15 & 41,1 & 14,4 \\
\hline
\end{tabular}

${ }^{(1)}$ Médias seguidas por letras iguais, nas colunas, não diferem estatistica-

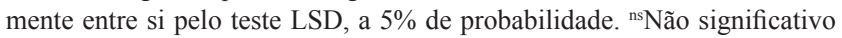
pelo teste $\mathrm{F}$, a $5 \%$ de probabilidade.

Tabela 3. Efeito da introdução de bactérias produtoras de biossurfactantes no substrato de cultivo de pepino hidropônico, 7 dias após a semeadura (uma aplicação), e 7 e 13 dias após a semeadura (duas aplicações), aos 20 dias após a segunda aplicação ${ }^{(1)}$.

\begin{tabular}{|c|c|c|c|}
\hline \multirow[t]{2}{*}{ Tratamento } & \multicolumn{2}{|c|}{ Massa de matéria seca $(\mathrm{g})$} & \multirow[t]{2}{*}{ Total } \\
\hline & Aérea & Radicular & \\
\hline & \multicolumn{3}{|c|}{ Uma aplicação dos microrganismos } \\
\hline Testemunha & $13,20 \mathrm{ab}$ & $7,48 \mathrm{~cd}$ & $20,78 \mathrm{ab}$ \\
\hline Gordonia rubripertincta SO-3B-2 & $13,40 \mathrm{ab}$ & $10,20 \mathrm{ab}$ & $23,60 \mathrm{a}$ \\
\hline Pseudomonas stutzeri MB-P3A-49 & $12,83 \mathrm{ab}$ & $10,59 \mathrm{a}$ & $23,42 \mathrm{a}$ \\
\hline Pseudomonas stutzeri MB-P3-C68 & $13,55 \mathrm{ab}$ & $8,23 \mathrm{abcd}$ & $21,78 \mathrm{ab}$ \\
\hline Pseudomonas stutzeri SO-3L-3 & $12,23 \mathrm{ab}$ & 9,00abcd & $21,25 \mathrm{ab}$ \\
\hline \multirow[t]{2}{*}{ Mistura de isolados } & $12,86 \mathrm{ab}$ & $8,74 \mathrm{abcd}$ & $21,60 \mathrm{ab}$ \\
\hline & \multicolumn{3}{|c|}{ Duas aplicações dos microrganismos } \\
\hline Testemunha & $13,20 \mathrm{ab}$ & $7,48 \mathrm{~cd}$ & $20,78 \mathrm{ab}$ \\
\hline Gordonia rubripertincta SO-3B-2 & $11,73 \mathrm{ab}$ & $8,44 \mathrm{abcd}$ & $20,16 a b$ \\
\hline Pseudomonas stutzeri MB-P3A-49 & $13,75 \mathrm{a}$ & $9,87 \mathrm{abc}$ & $23,61 \mathrm{a}$ \\
\hline Pseudomonas stutzeri MB-P3-C68 & $11,98 \mathrm{ab}$ & 7,94bcd & $19,92 \mathrm{ab}$ \\
\hline Pseudomonas stutzeri SO-3L-3 & $12,86 \mathrm{ab}$ & $8,11 \mathrm{abcd}$ & $20,97 \mathrm{ab}$ \\
\hline Mistura de isolados & $11,40 \mathrm{~b}$ & $6,83 \mathrm{~d}$ & $18,23 \mathrm{~b}$ \\
\hline CV $(\%)$ & 25,1 & 41,7 & 28,9 \\
\hline
\end{tabular}

$41 \%$, respectivamente (Tabela 3 ). Houve aumento de $14 \%$ na massa de matéria seca total das plantas com uma única aplicação de G. rubripertincta SO-3B-2 no substrato, e uma (13\%) ou duas (14\%) aplicações de P. stutzeri MB-P3A-49 no substrato de cultivo (Tabela 3). Embora o mecanismo de promoção de crescimento não tenha sido avaliado neste trabalho, a produção de hormônios do grupo das auxinas, por bactérias promotoras de crescimento de plantas, tem sido relatada como um dos mecanismos responsáveis pela promoção de desenvolvimento do sistema radicular (Suckstorff \& Berg, 2003). Além de produzir hormônios que estimulam o crescimento, as bactérias promovem o crescimento das plantas ao solubilizar fosfatos, fixar nitrogênio, degradar compostos tóxicos no solo e controlar o metabolismo de estresse, pela diminuição dos níveis de etileno vegetal (Lugtenberg \& Kamilova, 2009).

Os diferentes resultados encontrados nos experimentos de promoção de crescimento com aplicação da mistura de isolados podem ser explicados pelas diferentes concentrações de inóculo utilizadas (Tabelas 2 e 3 ). Suckstorff \& Berg (2003) também verificaram diferenças na resposta das plantas quanto à promoção de crescimento do sistema radicular, quando diferentes densidades de inóculo da bactéria Stenotrophomonas maltophilia foram aplicadas em plantas de morango. De acordo com Kloepper et al. (1980), a falha na colonização radicular por isolados bacterianos é responsável pela inconsistência dos resultados de promoção de crescimento. A aplicação da mistura de isolados na concentração de $1 \times 10^{9} \mathrm{ufc} \mathrm{mL}^{-1}$ pode ter causado competição entre os isolados, o que ocasionou a não promoção de crescimento; é provável que este problema não seja encontrado com concentração inferior de inóculo $\left(1 \times 10^{6}\right.$ células $\left.\mathrm{mL}^{-1}\right)$.

Ao considerar-se a similaridade entre o ambiente hidropônico e o dos manguezais, sugere-se que sejam realizados estudos mais detalhados com os isolados de B. cereus AVIC-3-6, G. rubripertincta SO-3B-2 e P. stutzeri MB-P3A-49.

\section{Conclusões}

1. Microrganismos de manguezais podem ter importância funcional no controle biológico da podridão radicular causada por Pythium aphanidermatum e na promoção do crescimento do pepineiro cultivado em hidroponia. 
2. Gordonia rubripertincta SO-3B-2 e Pseudomonas stutzeri MB-P3A-49 são bactérias promissoras para a promoção de crescimento das plantas não infestadas com o patógeno.

\section{Agradecimentos}

Ao Dr. Itamar Soares de Melo, coordenador do Projeto Manguezais da Biota, da Fundação de Amparo à Pesquisa do Estado de São Paulo, pelo auxílio na realização do trabalho.

\section{Referências}

BASHAN, Y.; HOLGUIN, G. Plant growth-promoting bacteria: a potential tool for arid mangrove reforestation. Trees: Structure and Function, v.16, p.159-166, 2002.

BETTIOL, W. Isolamento seletivo de Bacillus. In: MELO, I.S. de; SANHUEZA, R.M.V. (Ed.). Métodos de seleção de microrganismos antagônicos a fitopatógenos: manual técnico. Jaguariúna: Embrapa-CNPMA, 1995. p.35-36. (Embrapa-CNPMA. Documentos, 1).

CHATTERTON, S.; SUTTON, J.C.; BOLAND, G.J. Timing Pseudomonas chlororaphis applications to control Pythium aphanidermatum, Pythium dissotocum, and root rot in hydroponic peppers. Biological Control, v.30, p.360-373, 2004

CORRÊA, E.B. Controle da podridão de raiz (Pythium aphanidermatum) e promoção de crescimento em alface hidropônica. 2006. 93p. Dissertação (Mestrado) - Universidade Federal de Lavras, Lavras.

CORRÊA, E.B.; BETTIOL, W.; SUTTON, J.C. Controle biológico da podridão radicular (Pythium aphanidermatum) e promoção de crescimento por Pseudomonas chlororaphis 63-28 e Bacillus subtilis GB03 em alface hidropônica. Summa Phytopathologica, v.36, p.275-281, 2010.

DE JONGHE, K.; DE DOBBELAERE, I.; SARRAZYN, R.; HÖFTE, M. Control of Phytophthora cryptogea in the hydroponic forcing of witloof chicory with the rhamnolipid-based biosurfactant formulation PRO1. Plant Pathology, v.54, p.219-226, 2005

KHAN, A.; SUTTON, J.C.; GRODZINSKI, B. Effects of Pseudomonas chlororaphis on Pythium aphanidermatum and root rot in peppers grown in small-scale hydroponic troughs. Biocontrol Science and Technology, v.13, p.615-630, 2003.

KLOEPPER, J.W.; SCHROTH, M.N.; MILLER, T.D. Effects of rhizosphere colonization by plant growth-promoting rhizobacteria on potato plant development and yield. Phytopathology, v.70, p.1078-1082, 1980
LIU, W.; SUTTON, J.C.; GRODZINSKI, B.; KLOEPPER, J.W.; REDDY, M.S. Biological control of Pythium root rot of chrysanthemum in small-scale hydroponic units. Phytoparasitica, v. 35, p. $159-178,2007$

LUGTENBERG, B.; KAMILOVA, F. Plant-Growth-Promoting Rhizobacteria. Annual Review of Microbiology, v.63, p.541-556, 2009.

NIELSEN, C.J.; FERRIN, D.M.; STANGHELLINI, M.E. Efficacy of biosurfactants in the management of Phytophthora capsici on pepper in recirculating hydroponic systems. Canadian Journal of Plant Pathology, v.28, p.450-460, 2006.

OWEN-GOING, N.; SUTTON, J.C.; GRODZINSKI, B. Relationship of Pythium isolates and sweet pepper plants in single-plant hydroponic units. Canadian Journal of Plant Pathology, v.25, p.155-167, 2003.

PAULITZ, T.C.; BÉLANGER, R.R. Biological control in greenhouse systems. Annual Review of Phytopathology, v.39, p.103-133, 2001

PAULITZ, T.C.; ZHOU, T.; RANKIN, L. Selection of rhizosphere bacteria for biological control of Pythium aphanidermatum on hydroponically-grown cucumber. Biological Control, v.2, p.226-237, 1992.

RAHIMIAN, M.K.; BANIHASHEMI, Z. A method for obtaining zoospores of Pythium aphanidermatum and their use in determining cucumber seedling resistance to damping-off. Plant Disease Report, v.63, p.658-661, 1979.

REYES, L.F. Diversidade de bactérias em manguezal e biodegradação de hidrocarbonetos poliaromáticos. 2009. 123p. Tese (Doutorado) - Universidade de São Paulo, São Paulo.

SAHOO, K.; DHAL, N.K. Potential microbial diversity in mangrove ecosystems: a review. Indian Journal of Marine Sciences, v.38, p.249-256, 2009.

SAS INSTITUTE. SAS user's guide: statistics. Version 9.1. Cary: SAS Institute, 2007.

SUCKSTORFF, I.; BERG, G. Evidence for dose-dependent effects on plant growth by Stenotrophomonas strains from different origins. Journal of Applied Microbiology, v.95, p.656-663, 2003.

SUTTON, J.C.; SOPHER, C.R.; OWEN-GOING, T.N.; LIU, W.; GRODZINSKI, B.; HALL, J.C.; BENCHIMOL, R.L. Etiology and epidemiology of Pythium root rot in hydroponic crops: current knowledge and perspectives. Summa Phytopathologica, v.32, p.307-321, 2006

ZHENG, J.; SUTTON, J.C.; YU, H. Interactions among Pythium aphanidermatum, roots, root mucilage, and microbial agents in hydroponic cucumbers. Canadian Journal of Plant Pathology, v.22, p.368-379, 2000.

Recebido em 21 de agosto de 2010 e aprovado em 3 de janeiro de 2011 